\title{
REVIEW
}

\section{Molecular pathogenesis of iron overload}

\section{Trinder, C Fox, G Vautier, J K Olynyk}

Our current understanding of iron absorption under normal conditions is presented, together with an overview of the clinical disorders of iron overload and the molecular processes that contribute to increased iron deposition in iron overload. Recently, a number of new genes involved in iron metabolism have been identified which is allowing the molecular mechanisms of iron absorption to be elucidated.

See end of article for authors' affiliations

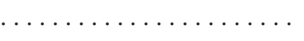

Correspondence to: Associate Professor J Olynyk, University Department of Medicine, PO Box 480, Fremantle 6959, Western Australia, Australia;

jolynyk@cyllene.uwa.edu.au

Accepted for publication 4 September 2001 ron homeostasis is controlled by the absorption of iron from the diet. It occurs mainly in the duodenum at a rate of approximately $1-2 \mathrm{mg}$ iron per day. When iron levels in the body or the diet are low, the rate of iron absorption is increased, and when iron levels are replete there is a reduction in the rate of iron absorption and excess iron is excreted when enterocytes are sloughed off every 2-3 days. Recently, a number of new genes involved in iron metabolism have been identified which is allowing the molecular mechanisms of iron absorption to be elucidated. In this review, our current understanding of iron absorption under normal conditions is presented followed by an overview of the clinical disorders of iron overload and the molecular processes that contribute to increased iron deposition in iron overload.

\section{MOLECULAR MECHANISMS OF IRON ABSORPTION}

Iron is found in the diet as ionic (non-haem) iron and haem iron. Absorption of these two forms of iron occurs by different mechanisms. Absorption is a multistep process involving the uptake of iron from the intestinal lumen across the apical cell surface of the villus enterocytes and the transfer out of the enterocyte across the basolateral membrane to the plasma. Ionic iron is present in the reduced (ferrous) or oxidised (ferric) state in the diet and the first step in the uptake of ionic iron involves the reduction of iron. Recently, a putative reductase that is capable of reducing iron from its ferric to ferrous state has been identified. It is a membrane bound haem protein called Dcytb that is expressed in the brush border of the duodenum. ${ }^{1}$ Next, ferrous ion is transported across the lumen cell surface by a transporter called divalent metal transporter 1 (DMTl) that can transport a number of other metal ions including copper, cobalt, zinc, and lead. ${ }^{2}$ Evidence for the role of DMTl in iron absorption is supported by studies in mk mice and Belgrade rat. Both of these laboratory animals have a G185R mutation in DMTl that inhibits iron uptake across the brush border leading to iron deficiency. ${ }^{3}$ Iron is then stored in the enterocyte or transferred out across the basolateral membrane by a membrane bound protein called ferroportin (also known as IREGl and MTP1). ${ }^{5-7}$ Extracellular ferrous iron is oxidised by the multi copper oxidase haephestin and bound by plasma transferrin. ${ }^{8}$

The mechanism of absorption of haem iron has yet to be elucidated. Transfer across the brush border membrane is probably mediated by an unidentified haem receptor. Once inside, enterocyte iron is released from haem by haem oxygenase and either stored or transferred out of the enterocyte by a mechanism that is likely to be similar to that for ionic iron (fig 1).

\section{REGULATION OF IRON ABSORPTION}

Iron absorption is regulated by a number of factors, including the level of body iron stores, the rate of erythropoiesis, and hypoxia. Enterocytes in the crypt region of the duodenal mucosa take up iron from plasma in proportion to the body's iron level, and the intracellular iron level in crypt cells reflects the body's iron status. ${ }^{10}$ Crypt cells express transferrin receptor 1 (TfRl) which mediates the uptake of transferrin bound iron (TBI). ${ }^{11}$ The haemochromatosis protein (HFE) is also highly expressed in crypt cells ${ }^{12}$ and forms a complex with $\beta_{2}$ microglobulin and TfR $1 .{ }^{13}$ The role of HFE in the regulation of TfRI mediated uptake of TBI is unclear. A number of studies in isolated cell systems have shown that HFE reduces both the affinity of TfRl for transferrin and the uptake of iron, due either to a reduction in the cycling time of the HFE/TfRI-TBI complex through the cell or a reduced rate of iron release from transferrin intracellularly ${ }^{14-17}$ Whereas when both HFE and $\beta_{2}$ microglobulin are overexpressed in Chinese Hamster Ovary cells, uptake of TBI was enhanced due to increased recycling of TfRl through the cell. ${ }^{18}$

A second transferrin receptor (TfR2) has been identified. ${ }^{19}$ TfR 2 mRNA is expressed at very low levels in the duodenum and does not interact with HFE in vitro. ${ }^{20}{ }^{21}$ Its role in iron absorption is yet to be determined.

In iron deficiency, DMTl, ferroportin, and TfRI are upregulated while ferritin is downregulated and the converse occurs when iron levels are increased. ${ }^{622-24}$ Expression of ferritin and TfRl is regulated by post-transcriptional mechanisms.

Abbreviations: DMT1, divalent metal transporter 1; HFE, haemochromatosis protein; $\mathrm{HH}$, hereditary haemochromatosis; IRE, iron regulatory element; IRP, iron regulatory protein; NTBI, non-transferrin bound iron; TBI, transferrin bound iron; TfR 1, transferrin receptor 1; TfR2, transferrin receptor 2 . 


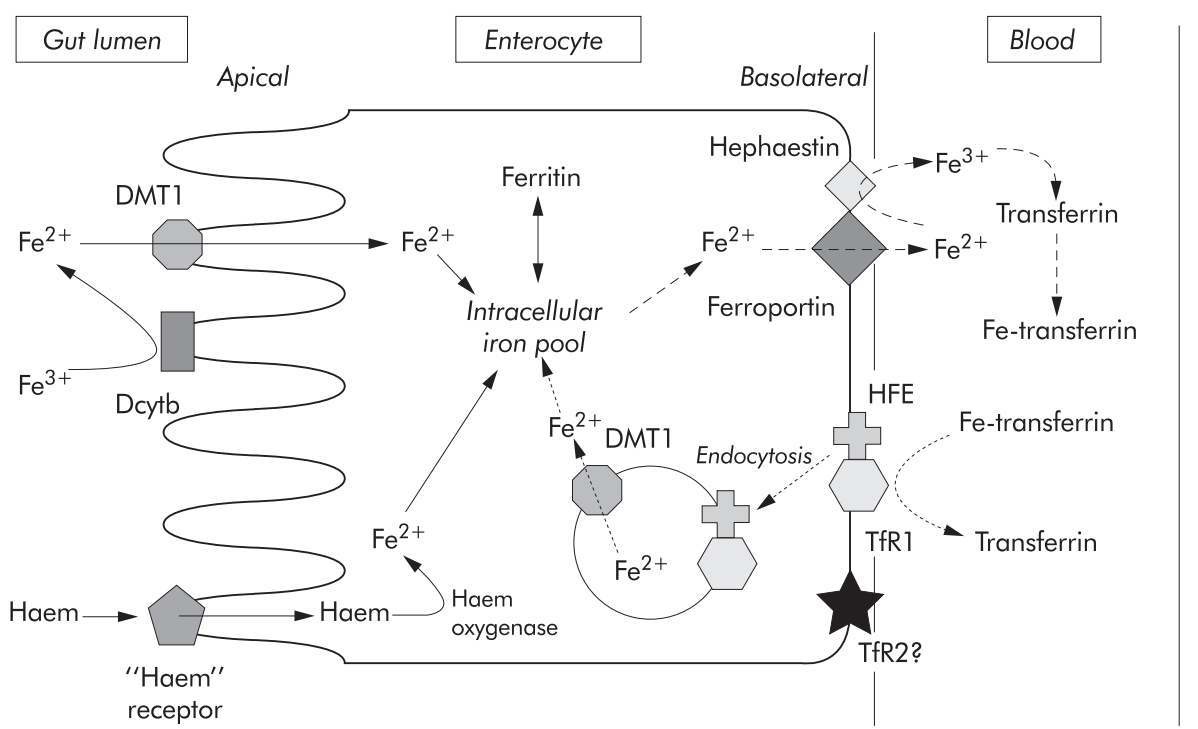

Figure 1 A model of the pathways of iron absorption by the enterocyte. The figure shows uptake of ionic iron and haem iron from the gut lumen and transfer of iron to blood. DMT1, divalent metal transporter 1; HFE, haemochromatosis protein, TfR 1, transferrin receptor 1; TfR2, transferrin receptor 2 .

The intracellular iron level controls the interaction of a cytosolic iron regulatory protein (IRP) with an iron regulatory element (IRE) in the untranslated region of the mRNA of these genes. ${ }^{25}$ HFE and TfR2 do not contain IRE and their expression is not iron regulated. ${ }^{19} 26$

IRP activity is one of the central regulators of iron absorption. IRP activity in crypt cells reflects the body's iron status. Crypt cells migrate to the villus region of the duodenum and differentiate into absorptive cells where the level of IRP binding activity, predetermined in crypts, regulates expression of iron transporters and the rate of iron absorption. ${ }^{27}$ Villus cells also respond to a change in iron levels in the diet. An iron gavage reduces IRP activity, DMTl expression, and iron absorption by villus cells within hours. ${ }^{28}$

Both the rate of erythropoiesis and hypoxia regulate iron absorption. ${ }^{29}$ Expression of ferroportin and Dcytb are upregulated in hypoxia and in a hypotransferrinaemic mouse which has chronic anaemia due to defective erythropoiesis. ${ }^{16}$ Increased expression of these genes is likely to account for the increase in iron absorption.

\section{CLINICAL SYNDROMES OF IRON OVERLOAD Hereditary haemochromatosis}

Clinical disorders of iron overload are classified in table 1 . In populations of Northern European ancestry, hereditary haemochromatosis $(\mathrm{HH})$ is the most common disorder of primary iron overload. This autosomal recessive disorder usually results from a homozygous mutation in the HFE gene of Anglo-Celtic populations. The clinical features of $\mathrm{HH}$ have been reviewed extensively. ${ }^{30}$

"In populations of Northern European ancestry, hereditary haemochromatosis is the most common disorder of primary iron overload"

The HFE gene was discovered in 1996 by Feder and colleagues $^{26}$ who described a novel gene containing two missense mutations. One of these mutations (Cys282 $\rightarrow$ Tyr; C282Y) was found to be homozygous in $83 \%$ of 178 patients with typical $\mathrm{HH}$ and has probably arisen in the last 2000 years, as estimated from ancestral haplotype studies. ${ }^{31}$ Studies from other groups of $\mathrm{HH}$ patients from Europe, the UK, and Australia have demonstrated that, on average, $85-90 \%$ of patients with $\mathrm{HH}$ are homozygous for the $\mathrm{C} 282 \mathrm{Y}$

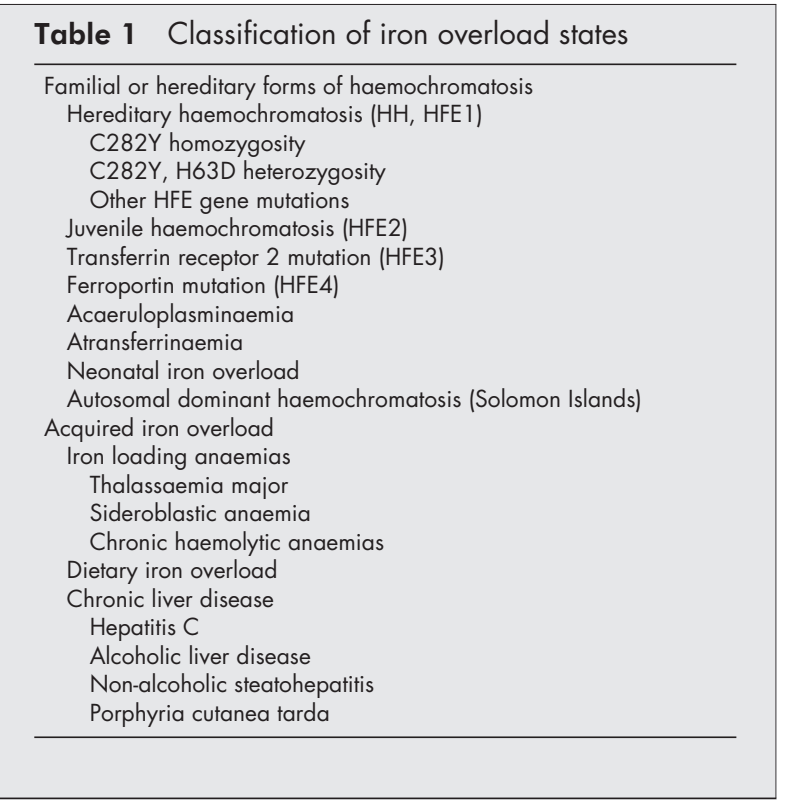

mutation..$^{32-34}$ A second mutation (His63 $\rightarrow$ Asp; H63D) was also identified but was not associated with the same degree of iron overload as the C282Y mutation. ${ }^{26}$ Lower frequencies of homozygosity for the C282Y mutation (64\%) are found in Southern European patients with $\mathrm{HH} .{ }^{35}$ The $\mathrm{C} 282 \mathrm{Y}$ mutation is rare in African, Asian, Polynesian, and indigenous Australian chromosomes. ${ }^{36}$

Other mutations within the HFE gene have been found that are associated with iron overload, usually in combination with C282Y heterozygosity: Mura et al reported enrichment of S65C missense substitution in patients with mild $\mathrm{HH}^{37}$ A novel splice site mutation causing skipping of exon 3 in the HFE locus has also been reported (IVS3 $+\mathrm{IG} \rightarrow \mathrm{T}$ ). ${ }^{38}$ Piperno et al found two novel missense mutations in five unrelated $\mathrm{HH}$ patients with C282Y heterozygosity. ${ }^{39}$

The role of mutations in the HFE gene as a cause of $\mathrm{HH}$ was further strengthened in 1998 when a knockout mouse model for the HFE gene was described. ${ }^{40}$ This model exhibited 
changes in iron metabolism and developed iron overload that were similar to humans with $\mathrm{HH}$.

\section{Clinical and biochemical expression of HFE gene mutations}

There is variable clinical expression of haemochromatosis protein (HFE) mutations in terms of the development of iron overload and clinical disease. Previous HLA based family studies suggested that almost all patients who had inherited the underlying genetic defect would develop iron overload. ${ }^{41}$ However, more recent studies of patients with $\mathrm{HH}$ have shown that up to $26 \%$ of subjects homozygous for the $\mathrm{C} 282 \mathrm{Y}$ mutation may not develop iron overload..$^{42}$ A large, systematic, Australian population based study has shown that 15 of 16 C282Y homozygotes are detected with an elevated transferrin saturation $\geqslant 45 \%$; $50 \%$ of homozygotes had typical clinical features and $25 \%$ had significant hepatic fibrosis or cirrhosis.

\section{"One in 700 individuals in an Anglo-Celtic population will have clinically significant iron overload but not possess mutations in the HFE gene"}

Progressive iron overload occurs in the majority of C282Y homozygotes. ${ }^{43}$ However, the frequency of biochemical expression varies with different populations. A study in blood donors in San Diego found that $36 \%$ of C282Y homozygotes had a transferrin saturation less than $45 \% .{ }^{44} \mathrm{Up}$ to $20 \%$ of patients heterozygous for both mutations (C282Y, H63D compound heterozygotes) demonstrate a clinical syndrome identical to that observed in C282Y homozygotes. ${ }^{45}$ Likewise, 1 in 700 individuals in an Anglo-Celtic population will have clinically significant iron overload but not possess mutations in the HFE gene. ${ }^{43}$ Cirrhosis and significant hepatic fibrosis are rarely observed in $\mathrm{C} 282 \mathrm{Y}$ homozygotes or compound heterozygotes under the age of 40 years, provided that no other hepatotoxins or hepatotropic viruses are present and serum ferritin level is less than $1000 \mathrm{ng} / \mathrm{ml}^{45-46}$

\section{Other genetic defects of iron metabolism}

Well defined kindreds exist with mutations outside the HFE gene. Juvenile haemochromatosis is an autosomal recessive disorder characterised by iron loading in the same pattern as adult $\mathrm{HH}$ but in the second or third decade of life. Roetta et al studied nine affected families and identified a locus on the long arm of chromosome 1 not known to correspond to a gene involved in iron metabolism. ${ }^{47}$ Juvenile haemochromatosis is now also termed HFE2. Camaschella et al reported a new locus on 7q22 and showed that a homozygous nonsense mutation in the gene encoding TfR2 is found in some individuals with non-HFE related iron overload. ${ }^{48}$ The disorder described by Camaschella et al is now also termed HFE3.

\section{"Juvenile haemochromatosis is an autosomal recessive disorder characterised by iron loading in the same pattern as adult $\mathrm{HH}$ but in the second or third decade of life"}

Pietrangelo et al studied a large Italian family in which 15 of 53 members had iron overload and none had C282Y mutations. Microsatellite analysis of the $\mathrm{HH}$ phenotype showed no linkage to the HFE gene. ${ }^{49}$ The iron overload disorder in these patients has now been linked to a mutation in the ferroportin gene and is termed HFE4. ${ }^{50}{ }^{51}$ The mechanisms underlying the development of iron overload in the HFE2HFE4 disorders are not clear.

Acaeruloplasminaemia is a rare genetic iron overload disorder that results in diabetes and neurodegenerative disease due to a mutation in the caeruloplasmin gene causing nonexpression of the gene product. Lack of caeruloplasmin reduces plasma ferroxidase activity and cellular release of iron causing progressive accumulation in the liver, pancreas, and brain. ${ }^{52}$ Atransferrinaemia is a very rare inherited disorder in which there is no plasma transferrin. Patients have enhanced iron absorption but the erythroid precursor cells are unable to utilise non-transferrin bound iron (NTBI) and thus respond as though there is severe iron deficiency. Excess NTBI accumulates in the liver, pancreas, and heart as the rate of iron release from these tissues is also reduced due to lack of transferrin. ${ }^{53}$ These patients require transferrin infusion for survival.

\section{Regulation of iron absorption in hereditary haemochromatosis}

In $\mathrm{HH}$ patients there is an increase in the rate of iron absorption. Enterocytes of HH patients have increased IRP activity and reduced ferritin levels. ${ }^{54}$ Furthermore, recent studies have shown that expression of the iron transporters DMTl and ferroportin are both upregulated in subjects with HFE-HH, nonHFE HH, and iron deficiency but not secondary iron overload. ${ }^{6556}$ Increased expression of DMTl mRNA and protein has also been observed in the intestine of the HFE knockout mouse model of $\mathrm{HH}$ inducing enhanced iron absorption. ${ }^{57}{ }^{58}$ However, this finding is controversial as others found no increase in DMTl mRNA and protein levels in the intestine of C282Y HFE and $\beta_{2}$ microglobulin knockout mouse models of iron overload. ${ }^{59}$

These observations indicate that there is an incorrect sensing of the body's iron level by the intestinal crypt cells in HH. In a recent study we have reported that HFE regulation of TBI uptake by the duodenum is impaired in the HFE knockout mouse model of $\mathrm{HH}^{60}$ This would lead to reduced intracellular iron levels in crypt cells of the duodenum that do not reflect correctly the high plasma iron levels found in HH. Thus enterocytes would be incorrectly programmed to absorb iron from the diet.

Exactly how C282Y HFE impairs the uptake of TBI from plasma by the duodenum is unknown. However, these findings are consistent with results obtained using Chinese Hamster Ovary cells described earlier where overexpression of wild-type HFE and $\beta_{2}$ microglobulin enhanced the uptake of TBI by increasing the rate of TfR I recycling through the cell. ${ }^{18}$ As it is known that the C282Y HFE does not associate with $\beta_{2}$ microglobulin and TfRl and its cell surface expression is reduced, ${ }^{61}{ }^{62}$ it is unlikely that $\mathrm{C} 282$ Y HFE could stimulate TBI uptake by Chinese Hamster Ovary cells as the wild-type HFE does. Therefore, a relative reduction in TBI uptake in the presence of C282Y HFE by Chinese Hamster Ovary cells would be consistent with reduced uptake of TBI by the duodenum of HFE knockout mice and by macrophages from patients with $\mathrm{HH}^{6063}$

\section{Molecular mechanisms of iron loading of the liver}

The liver is the main site of iron storage and most of the iron is deposited in hepatocytes as ferritin or haemosiderin. In iron overload the rate of iron uptake exceeds the rate of iron release by hepatocytes resulting in increased hepatic iron levels. Usually iron is transported in plasma by transferrin. However, in iron overload, transferrin becomes saturated with iron and excess iron or NTBI is also present. The hepatocyte can take up both NTBI and TBI and both sources are likely to contribute to elevated hepatic iron deposition in iron overload.

\section{"In iron overload the rate of iron uptake exceeds the rate of iron release by hepatocytes resulting in increased hepatic iron levels"}

Functional studies have shown that uptake of TBI by the hepatocyte occurs by TfRl and TfRl independent pathways. Hepatocytes express only a low number of TfRl receptors and the main pathway of TBI uptake by hepatocytes and hepatoma 


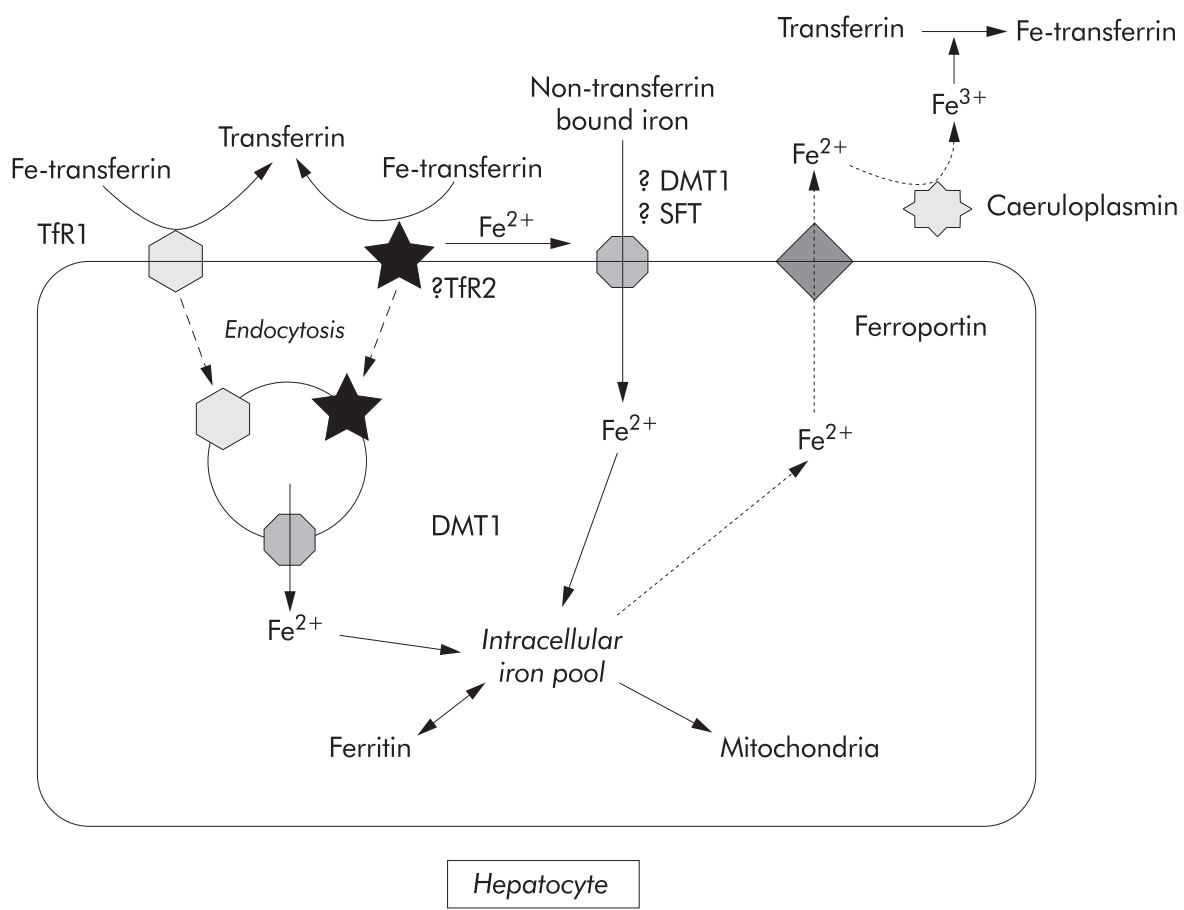

Figure 2 Diagrammatic representation of the pathways of uptake of transferrin bound iron and non-transferrin bound iron by hepatocytes (see text for explanation). TfR 1, transferrin receptor 1; TfR2, transferrin receptor 2; DMT1, divalent metal transporter 1; SFT, stimulator of iron transport.

cell lines is thought to be mediated by low affinity TfRl independent pathways. ${ }^{64}{ }^{65}$ The first of the TfRl independent pathways involves endocytosis of TBI while the second involves release of iron from transferrin at the cell surface and transport into the cell by an iron transporter that also mediates uptake of NTBI. ${ }^{66}{ }^{67}$ TfR2 2 is highly expressed in human liver. ${ }^{19}$ Its role in hepatic iron transport is yet to be established but it is likely that TfR2 mediates uptake of iron by the TfRl independent pathway (fig 2).

TfRl expression by hepatocytes is downregulated by iron loading..$^{208}$ In fact there is complete absence of TfRl expression in $\mathrm{HH}$ patients ${ }^{69}$ and in the HFE knockout mouse, ${ }^{20}$ and therefore TfRl mediated uptake of TBI is unlikely to contribute significantly to iron loading of the liver. TfR2 does not contain an IRE and its expression in the liver is not iron regulated. In the HFE knockout mouse, TfR2 expression remains high and TfR2 mediated uptake of iron could contribute to loading of the liver in $\mathrm{HH}^{20}$

NTBI is extremely toxic, can generate free radicals, and is rapidly cleared from plasma by the liver. ${ }^{70}$ Hepatocytes take up NTBI by a process that involves iron reduction and transport across the cell membrane by a carrier mediated process ${ }^{71-73}$ which may involve the iron transporters DMTl or stimulator of iron transport. ${ }^{74}$ Both the uptake of NTBI and expression of DMTl in the liver have been shown to be enhanced by iron loading and this process may contribute to iron loading of the liver. ${ }^{23} 71$

The mechanism of iron release by hepatocytes is not well understood. Ferroportin is localised to the hepatocyte cell membrane and is a likely candidate for the transporter of iron out of cells. ${ }^{7}$ Iron is then oxidised by caeruloplasmin and bound by plasma transferrin (fig 2). ${ }^{75}$ Further studies need to be undertaken to establish if ferroportin expression and the rate of iron release are altered with iron loading.

HFE is not expressed in hepatocytes and therefore is not likely to play a role in the regulation of iron transport in hepatocytes. ${ }^{12}{ }^{76} \mathrm{In} \mathrm{HH}$, iron metabolism of hepatocytes is not directly affected by mutations in the HFE protein but rather, increases in plasma TBI and NTBI contribute to elevated iron levels and subsequent liver damage.
"Recently, the hepatic antimicrobial peptide hepcidin has been identified as a potential new player in iron metabolism"

Recently, the hepatic antimicrobial peptide hepcidin has been identified as a potential new player in iron metabolism. Interestingly, a transcription factor USF2 knockout mouse which lacks hepcidin expression developed iron overload that was similar to $\mathrm{HH}^{77}$ However, others have shown that hepatic hepcidin levels are upregulated in iron overload. ${ }^{78}$ Thus the role of hepcidin in iron homeostasis is unclear but it may act as a signalling molecule that regulates hepatic iron levels and the rate of iron absorption.

\section{Mechanisms of iron induced liver injury}

The mechanisms by which iron may cause liver disease have been reviewed. ${ }^{79}$ Studies that have examined collagen gene expression in iron overload have indicated that iron deposition in hepatocytes is necessary since, if iron is not present in hepatocytes, collagen gene expression is not increased..$^{80}$ These data suggest that either iron loaded hepatocytes directly release profibrogenic substances, which activate hepatic stellate cells (the principal cellular sources of collagen and other matrix proteins in chronic liver disease) or release substances which stimulate Kupffer cells to produce profibrogenic substances which activate hepatic stellate cells. Iron overload can induce lipid peroxidation of organic membranes leading to cell injury and cell death. Lipid peroxidation products have been shown to stimulate collagen production in activated hepatic stellate cells and cultured human fibroblasts. ${ }^{81}$ Alternatively, lipid peroxidation products may increase production of transforming growth factor $\beta$ or other profibrogenic substances by Kupffer cells which might then stimulate hepatic stellate cell activation. ${ }^{82}$ Hepatocellular carcinoma could result from DNA damage from iron induced adduct formation and chromosomal damage ${ }^{83}$ or proliferation and dedifferentiation of hepatic stem cells termed "oval cells". ${ }^{84}$ 


\section{CONCLUSION}

There have been significant advances in recognising the evolving phenotype of iron overload syndromes and their associated genotypes over the last five years, although there are likely to be further candidate genes identified. However, reconciling the mechanisms by which the various iron transport genes and proteins contribute to normal homeostasis of iron metabolism is far from complete. Candidate mutations in iron transport genes and abnormal protein functions have been described predominantly at the molecular and isolated cell levels. Attempts to confirm these observations at the whole organism level have either proved difficult or have not been attempted. Clearly, the key to "ironing out" the molecular pathogenesis of iron overload disorders depends on the ability to correlate events at the gene, RNA, and protein levels with functional outcomes in the whole organism.

\section{ACKNOWLEDGEMENTS}

Grant support was obtained from the National Health and Medical Research Council of Australia; Fremantle Hospital Medical Research Foundation; and Cancer Foundation of Western Australia

\section{Authors' affiliations}

D Trinder, Department of Medicine and Western Australian Institute for Medical Research, University of Western Australia, Australia

C Fox, Department of Gastroenterology, Fremantle Hospital, Fremantle, Western Australia, Australia

G Vautier, Department of Gastroenterology, Fremantle Hospital, Fremantle, Western Australia, Australia, and Royal Defence Medical College, Gosport, UK

J K Olynyk, Department of Medicine and Western Australian Institute for Medical Research, University of Western Australia, Australia, and Department of Gastroenterology, Fremantle Hospital, Fremantle, Western Australia, Australia

\section{REFERENCES}

1 McKie AT, Barrow D, Latunde-Dada GO, et al. An iron-regulated ferric reductase associated with the absorption of dietary iron. Science 2001;291:1755-9.

2 Gunshin H, Mackenzie B, Berger UV, et al. Cloning and characterization of a mammalian proton-coupled metal-ion transporter Nature 1997;388:482-8

3 Fleming MD, Romano MA, Su MA, et al. Nramp2 is mutated in the anemic Belgrade (b) rat: evidence of a role for Nramp2 in endosomal iron transport. Proc Natl Acad Sci USA 1998;95:1148-53.

4 Fleming MD, Trenor CC3, Su MA, et al. Microcytic anaemia mice have a mutation in Nramp2, a candidate iron transporter gene. Nat Genet 1997; 16:383-6

5 Donovan A, Brownlie A, Zhou Y, et al. Positional cloning of zebrafish ferroportin 1 identifies a conserved vertebrate iron exporter. Nature 2000;403:776-81

6 McKie AT, Marciani P, Rolfs A, et al. A novel duodenal iron-regulated transporter, IREG 1, implicated in the basolateral transfer of iron to the circulation. Molecular Cell 2000;5:299-309.

7 Abboud S, Haile DJ. A novel mammalian iron-regulated protein involved in intracellular iron metabolism. J Biol Chem 2000;275:19906-12.

8 Vulpe CD, Kuo YM, Murphy TL, et al. Hephaestin, a ceruloplasmin homologue implicated in intestinal iron transport, is defective in the sla mouse. Nat Genet 1999;21:195-9.

9 Skikne B, Baynes RD. Iron absorption. In: Brock JH, Halliday JW Pippard M, et al, eds. Iron metabolism in health and disease. London: WB Saunders, 1994:151-87.

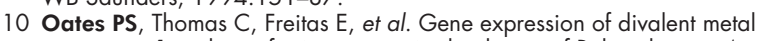
transporter 1 and transferrin receptor in duodenum of Belgrade rats. Am J Physiol 2000;278:G930-6.

11 Anderson GJ, Powell LW, Halliday JW. Transferrin receptor distribution and regulation in the rat small intestine. Effect of iron stores and erythropoiesis. Gastroenterology 1990;98:576-85.

12 Parkkila S, Waheed A, Britton RS, et al. Immunohistochemistry of HLA-H, the protein defective in patients with hereditary hemochromatosis, reveals unique pattern of expression in gastrointestinal tract. Proc Natl Acad Sci USA 1997;94:2534-9

13 Waheed A, Parkkila S, Saarnio J, et al. Association of HFE protein with transferrin receptor in crypt enterocytes of human duodenum. Proc Natl Acad Sci USA 1999;96:1579-84.

14 Feder JN, Penny DM, Irrinki A, et al. The hemochromatosis gene product complexes with the transferrin receptor and lowers its affinity for ligand binding. Proc Natl Acad Sci USA 1998;95:1472-7.

15 Roy CN, Penny DM, Feder JN, et al. The hereditary hemochromatosis protein, HFE, specifically regulates transferrin-mediated iron uptake in HeLa cells. J Biol Chem 1999;274:9022-8.
16 Salter-Cid L, Brunmark A, Li Y, et al. Transferrin receptor is negatively modulated by the hemochromatosis protein HFE: implications for cellular iron homeostasis. Proc Natl Acad Sci USA 1999;96:5434-9.

17 Ikuta K, Fujimoto Y, Suzuki Y, et al. Overexpression of hemochromatosis protein, HFE, alters transferrin recycling process in human hepatoma cells. Biochim Biophys Acta 2000;1496:221-31.

18 Waheed A, Grubb JH, Zhou XY, et al. Regulation of transferrin-mediated iron uptake by HFE, the protein defective in hereditary hemochromatosis. Proc Natl Acad Sci USA 2002;99:3117-22.

19 Kawabata H, Yang R, Hirama T, et al. Molecular cloning of transferrin receptor 2. A new member of the transferrin receptor-like family. J Biol Chem 1999;274:20826-32

20 Fleming RE, Migas MC, Holden CC, et al. Transferrin receptor 2: continued expression in mouse liver in the face of iron overload and in hereditary hemochromatosis. Proc Natl Acad Sci USA 2000:97:2214-19.

21 West APJ, Bennett M, Sellers VM, et al. Comparison of the interactions of transferrin receptor and transferrin receptor 2 with transferrin and the hereditary hemochromatosis protein HFE. J Biol Chem 2000;275:38135-8

22 Canonne-Hergaux F, Gruenheid S, Ponka P, et al. Cellular and subcellular localization of the Nramp2 iron transporter in the intestinal brush border and regulation by dietary iron. Blood 1999;93:4406-17.

23 Trinder D, Oates PS, Thomas C, et al. Localisation of divalent metal transporter 1 (DMT1) to the microvillus membrane of rat duodenal enterocytes in iron deficiency, but to hepatocytes in iron overload. Gut 2000;46:270-6

24 Pietrangelo A, Rocchi E, Casalgrandi G, et al. Regulation of transferrin, transferrin receptor, and ferritin genes in human duodenum. Gastroenterology 1992;102:802-9.

25 Klausner RD, Rouault TA, Harford JB. Regulating the fate of mRNA: the control of cellular iron metabolism. Cell 1993:72:19-28.

26 Feder JN, Gnirke A, Thomas W, et al. A novel MHC class I-like gene is mutated in patients with hereditary haemochromatosis. Nat Genet 1996; 13:399-408.

27 Schumann $\mathbf{K}$, Moret R, Kunzle $\mathrm{H}$, et al. Iron regulatory protein as an endogenous sensor of iron in rat intestinal mucosa. Possible implications for the regulation of iron absorption. Eur J Biochem 1999;260:362-72.

28 Oates PS, Trinder D, Morgan EH. Gastrointestinal function, divalent metal transporter-1 expression and intestinal iron absorption. Pflugers Archiv Eur J Physiol 2000;440:496-502.

29 Raja KB, Simpson RJ, Pippard M, et al. In vivo studies on the relationship between intestinal iron $(\mathrm{Fe} 3+)$ absorption, hypoxia and erythropoiesis in the mouse. Br J Haematol 1988;68:373-8.

30 Bacon BR, Powell LW, Adams PC, et al. Molecular medicine and hemochromatosis: at the crossroads. Gastroenterology 1999; 116:193-207.

31 Rochette J, Pointon JJ, Fisher CA, et al. Multicentric origin of hemochromatosis gene (HFE) mutations. Am J Hum Genet 1999;64: 1056-62

32 Beutler E, Gelbart T, West C, et al. Mutation analysis in hereditary hemochromatosis. Blood Cells Mol Dis 1996;22:187-94.

33 The UK Haemochromatosis Consortium A simple genetic test identifies $90 \%$ of UK patients with haemochromatosis. Gut 1997;41:841-4

34 Jazwinska EC, Cullen LM, Busfield F, et al. Haemochromatosis and HLA-H. Nat Genet 1996:14:249-51.

35 Carella M, D'Ambrosio L, Totaro A, et al. Mutation analysis of the HLA-H gene in Italian hemochromatosis patients. Am J Hum Genet 1997;60:828-32

36 Merryweather-Clarke AT, Pointon JJ, Shearman JD, et al. Global prevalence of putative haemochromatosis mutations. J Med Genet 1997;34:275-8.

37 Mura C, Raguenes O, Ferec C. HFE mutations analysis in 711 hemochromatosis probands: evidence for $\mathrm{S} 65 \mathrm{C}$ implication in mild form of hemochromatosis. Blood 1999;93:2502-5.

38 Wallace DF, Dooley JS, Walker AP. A novel mutation of HFE explains the classical phenotype of genetic hemochromatosis in a C282Y heterozygote. Gastroenterology 1999;1 16:1409-12

39 Piperno A, Arosio C, Fossati L, et al. Two novel nonsense mutations of HFE gene in five unrelated Italian patients with hemochromatosis. Gastroenterology 2000;1 19:441-5.

40 Zhou XY, Tomatsu S, Fleming RE, et al. HFE gene knockout produces mouse model of hereditary hemochromatosis. Proc Natl Acad Sci USA 1998;95:2492-7

41 Edwards CQ, Griffen LM, Goldgar D, et al. Prevalence of hemochromatosis among 11,065 presumably healthy blood donors. $N$ Engl J Med 1988;318:1355-62.

42 Adams PC, Chakrabarti S. Genotypic/phenotypic correlations in genetic hemochromatosis: evolution of diagnostic criteria. Gastroenterology 1998;114:319-23.

43 Olynyk JK, Cullen DJ, Aquilia S, et al. A population-based study of the clinical expression of the hemochromatosis gene. N Engl J Med 1999;341:718-24.

44 Beutler E, Felitti V, Gelbart T, et al. The effect of HFE genotypes on measurements of iron overload in patients attending a health appraisal clinic. Ann Intern Med 2000;133:329-37.

45 Bacon BR, Olynyk JK, Brunt EM, et al. HFE genotype in patients with hemochromatosis and other liver diseases. Ann Intern Med 1999;130:953-62.

46 Guyader D, Jacquelinet C, Moirand R, et al. Noninvasive prediction of fibrosis in C282Y homozygous hemochromatosis. Gastroenterology 1998; 115:929-36. 
47 Roetto A Totaro A, Cazzola $M$, et al Juvenile hemochromatosis locus maps to chromosome 1q. Am J Hum Genet 1999;64:1388-93.

48 Camaschella C, Roetto A, Cali A, et al. The gene TFR2 is mutated in a new type of haemochromatosis mapping to 7q22. Nat Genet 2000;25:14-15.

49 Pietrangelo A, Montosi G, Totaro A, et al. Hereditary hemochromatosis in adults without pathogenic mutations in the hemochromatosis gene. $N$ Engl J Med 1999;341:725-32.

50 Niajou OT, Vaessen N, Joosse M, et al. A mutation in SLC1 1A3 is associated with autosomal dominant haemochromatosis. Nat Genet 2001:28:213-14.

51 Montosi G, Donovan A, Totaro A, et al. Autosomal-dominan haemochromatosis is associated with a mutation in the ferroportin (SLC1 1A3) gene. J Clin Invest 2001;108:619-23.

52 Gitlin JD. Aceruloplasminemia. Pediatr Res 1998:44:271-6.

53 Hayashi A, Wada Y, Suzuki T, et al. Studies on familial hypotransferrinemia: unique clinical course and molecular pathology. Am J Hum Genet 1993;53:201-13

54 Pietrangelo A, Casalgrandi G, Quaglino D, et al. Duodenal ferritin synthesis in genetic hemochromatosis. Gastroenterology 1995; 108:208-17.

55 Zoller H, Pietrangelo A, Vogel W, et al. Duodenal metal-transporter (DMT-1, NRAMP-2) expression in patients with hereditary haemochromatosis. Lancet 1999;353:2120-3.

56 Zoller H, Koch RO, Theurl I, et al. Expression of the duodenal iron transporters divalent-metal transporter 1 and ferroportin 1 in iron deficiency and iron overload. Gastroenterology 2001;120:1412-19.

57 Griffiths WJ, Sly WS, Cox TM. Intestinal iron uptake determined by divalent metal transporter is enhanced in HFE-deficient mice with hemochromatosis. Gastroenterology 2001;120:1420-9.

58 Fleming RE, Migas MC, Zhou X, et al. Mechanism of increased iron absorption in murine model of hereditary hemochromatosis: increased duodenal expression of the iron transporter DMT1. Proc Natl Acad Sci USA 1999:96:3143-8

59 Canonne-Hergaux $\mathbf{F}$, Levy JE, Fleming MD, et al. Expression of the DMT1 (NRAMP2/DCT1) iron transporter in mice with genetic iron overload disorders. Blood 2001;97:1138-40.

60 Trinder D, Olynyk JK, Sly WS, et al. Iron uptake from plasma transferrin by the duodenum is impaired in the Hfe knockout mouse. Proc Natl Acad Sci USA 2002:99:5622-6.

61 Feder JN, Tsuchihashi Z, Irrinki A, et al. The hemochromatosis founder mutation in HLA-H disrupts beta2-microglobulin interaction and cell surface expression. J Biol Chem 1997;272:14025-8.

62 Waheed A, Parkkila S, Zhou XY, et al. Hereditary hemochromatosis: effects of $\mathrm{C} 282 \mathrm{Y}$ and $\mathrm{H} 63 \mathrm{D}$ mutations on association with beta2-microglobulin, intracellular processing, and cell surface expression of the HFE protein in COS-7 cells. Proc Natl Acad Sci USA 1997;94:12384-9.

63 Montosi G, Paglia P, Garuti C, et al. Wild-type HFE protein normalises transferrin iron accumulation in macrophages from subjects with hereditary hemochromatosis. Blood 2000;96:1125-9.

64 Baker E, Morgan EH. Iron transport. In: Brock JH, Halliday JW, Pippard $\mathrm{M}$, et al, eds. Iron metabolism in health and disease. London: WB Saunders, 1994:63-95.

65 Trinder D, Morgan EH. Uptake of transferrin-bound iron by mammalian cells. In: Templeton D, ed. Molecular and cellular iron transport. New York: Marcel Dekker, 2002:427-50.
66 Trinder D, Zak O, Aisen P. Transferrin receptor-independent uptake of diferric transferrin by human hepatoma cells with antisense inhibition of receptor expression. Hepatology 1996;23:1512-20.

67 Trinder D, Morgan E. Inhibition of uptake of transferrin-bound iron by human hepatoma cells by nontransferrin-bound iron. Hepatology 1997;26:691-8.

68 Trinder D, Batey RG, Morgan EH, et al. Effect of cellular iron concentration on iron uptake by hepatocytes. Am J Physiol 1990;259:G611-17

69 Sciot R, Paterson AC, Van den Oord JJ, et al. Lack of hepatic transferrin receptor expression in hemochromatosis. Hepatology 1987;7:831-7.

70 Wright TL, Brissot $\mathrm{P}, \mathrm{Ma} \mathrm{WL}$, et al. Characterization of non-transferrin-bound iron clearance by rat liver. J Biol Chem 1986;261:10909-14.

71 Randell EW, Parkes JG, Olivieri NF, et al. Uptake of non-transferrin-bound iron by both reductive and nonreductive processes is modulated by intracellular iron. J Biol Chem 1994;269: 16046-53.

72 Baker E, Baker SM, Morgan EH. Characterisation of non-transferrin-bound iron (ferric citrate) uptake by rat hepatocytes in culture. Biochim Biophys Acta 1998;1380:21-30

73 Trinder D, Morgan E. Mechanisms of ferric citrate uptake by human hepatoma cells. Am J Physiol 1998;275:G279-86.

74 Gutierrez JA, Yu J, Rivera S, et al. Functional expression cloning and characterization of SFT, a stimulator of Fe transport. J Cell Biol 1997; 139:895-905.

75 Harris ZL, Durley AP, Man TK, et al. Targeted gene disruption reveals an essential role for ceruloplasmin in cellular iron efflux. Proc Natl Acad Sci USA 1999;96:10812-17.

76 Bastin JM, Jones M, O'Callaghan CA, et al. Kupffer cell staining by an HFE-specific monoclonal antibody: implications for hereditary haemochromatosis. Br J Haematol 1998;103:931-41.

77 Nicolas G, Bennoun M, Devaux I, et al. Lack of hepcidin gene expression and severe tissue iron overload in upstream stimulatory factor 2 (USF2) knockout mice. Proc Natl Acad Sci USA 2001;98:8780-5.

78 Pigeon C, llyin G, Courseload B, et al. A new mouse liver-specific gene, encoding a protein homologous to human antimicrobial peptide hepcidin, is overexpressed during iron overload. J Biol Chem 2001;276:7811-19.

79 Britton RS, Ramm GA, Olynyk J, et al. Pathophysiology of iron toxicity. Adv Exp Med Biol 1994;356:239-53.

80 Gualdi R, Casalgrandi G, Montosi G, et al. Excess iron into hepatocytes is required for activation of collagen type I gene during experimental siderosis. Gastroenterology 1994;107:1118-24.

81 Maher JJ, Zia S, Tzagarakis C. Acetaldehyde-induced stimulation of collagen synthesis and gene expression is dependent on conditions of cell culture: studies with rat lipocytes and fibroblasts. Alcohol Clin Exp Res 1994; 18:403-9.

82 Leonarduzzi G, Scavazza A, Biasi $F$, et al. The lipid peroxidation end product 4 -hydroxy-2,3-nonenal up-regulates transforming growth factor beta 1 expression in the macrophage lineage: a link between oxidative injury and fibrosclerosis. FASEB J 1997;11:851-7.

83 Nordenson I, Ritter B, Beckman A, et al. Idiopathic hemochromatosis and chromosomal damage. Hum Hered 1992;42:143-5.

84 Lowes KN, Brennan BA, Yeoh GC, et al. Oval cell numbers in human chronic liver diseases are directly related to disease severity. Am J Pathol $1999 ; 154: 537-41$ 